https://doi.org/10.22319/rmcp.v9i3.4364

Artículo

\title{
Frecuencia de casos e identificación molecular de Cryptosporidium spp. en corderos lactantes mantenidos en pastoreo en el estado de Veracruz, México
}

\section{Cases frequency and molecular identification of Cryptosporidium spp. in lactating lambs kept grazing in the State of Veracruz, Mexico}

Irene Vitela-Mendoza ${ }^{a^{*}}$

Victor Guillen Lorenzo ${ }^{\mathrm{a}}$

Carlos Cruz-Vázquez ${ }^{a}$

Leticia Medina-Esparza ${ }^{a}$

Miguel Ramos Parra ${ }^{\mathrm{a}}$

a El Llano Aguascalientes, Km. 18 carretera Aguascalientes-San Luis Potosí, 20330, El Llano, Aguascalientes, México. Tel. 4499621100.

* Autor de correspondencia: vitelairene@yahoo.com.mx

\section{- Resumen:}

El objetivo fue determinar la frecuencia de la infección por Cryptosporidium spp., y realizar la identificación de especie o genotipo de los ooquistes en corderos lactantes Pelibuey, Black Belly y Katahdin mantenidos en pastoreo en la región de la Huasteca Alta del estado de Veracruz, México. Las muestras de excremento se recolectaron de 210 corderos de 7 a 21 días de edad, procedentes de 21 granjas; se procesaron mediante frotis fecal teñido con Kinyoun y por PCR anidada para amplificar la región del gen 18S rARN del parásito (830 $\mathrm{pb}$ ) las muestras positivas fueron secuenciadas. La frecuencia de corderos positivos a Cryptosporidium spp., por microscopía fue $19.5 \%$ (41/210), con una escala entre rebaños de 10 a $50 \%$; en tanto que por técnicas moleculares fue de $26.8 \%(11 / 41)$ con un intervalo de 14 a $50 \%$; las demás muestras fueron negativas a ambas pruebas. Las 11 muestras 
secuenciadas tuvieron una homología del $100 \%$ con la región $18 \mathrm{~S}$ rARN de C. parvum. Estos resultados confirman la importancia de $C$. parvum como principal agente de la criptosporidiosis en corderos lactantes y su amplia distribución en esta región de México. Esta identificación destaca que las ovejas pueden considerarse como una fuente potencial notable de criptosporidiosis humana, porque se considera una enfermedad zoonótica, principalmente para las personas que manipulan los rebaños.

- Palabras clave: Cryptosporidium parvum, Corderos, Frecuencia, Genotipificación.

\begin{abstract}
- Abstract:
The objective was to determine the frequency of Cryptosporidium spp., and to identify the species or genotype of the oocysts found, in suckling lambs kept grazing in the Huasteca Alta region, State of Veracruz, Mexico. Fecal samples were collected from 210 lambs Pelibuey, Black Belly, and Katahdin, 7 to $21 \mathrm{~d}$ old from 21 sheep farms. Samples were stained with Kinyoun, nested PCR was used to amplify the 18S rRNA gene region of the parasite (830 $\mathrm{bp}$ ), and positive samples were sequenced. The frequency of animals positive to Cryptosporidium spp by microscopy was $19.5 \%$ (41/210), with a 10 to $50 \%$ range among herds; with molecular techniques, the frequency of positive lambs was $26.8 \%(11 / 41)$ with a 14 to $50 \%$ range; all other samples were negative to both tests. All 11 samples sequenced

showed $100 \%$ homology with the $18 \mathrm{~S}$ rRNA region of $C$. parvum. Results confirm the relevance of $C$. parvum as a major etiology of cryptosporidiosis in lactating lambs and show its broad distribution in this region of Mexico. This identification highlights that sheep can be considered as a significant potential source of human cryptosporidiosis, since it is considered a zoonotic disease, mainly for the people handling the flocks.
\end{abstract}

- Key words: Cryptosporidium parvum, Lambs, Frequency, Genotyping.

Recibido 07/02/2017

Aceptado 12/12/2017

\title{
N Introducción
}

Cryptosporidium spp., es un parásito protozoario que causa infección entérica en varias especies animales, así como en los seres humanos, y es un importante problema de salud 
animal, así como de salud pública, principalmente en individuos jóvenes o inmunocomprometidos; los ooquistes del parásito son resistentes al medio ambiente y pueden contaminar agua y alimentos ${ }^{(1,2,3)}$. En los ovinos, la criptosporidiosis se presenta con un cuadro de diarrea de leve a severa, de color amarillento con un fuerte olor, acompañada de dolor abdominal, pérdida de peso, depresión, y eventualmente la muerte; es más frecuente en corderos lactantes a partir de su nacimiento y hasta un mes de edad ${ }^{(4,5)}$. Cryptosporidium spp., es uno de los principales patógenos entéricos asociados con diarrea neonatal y mortalidad en corderos; los borregos adultos asintomáticos son una importante fuente de infección para los animales jóvenes y la principal condición de diseminación dentro de la granja ${ }^{(6)}$. Las especies de Cryptosporidium identificadas en ovinos son: C. parvum, C. xiaoi y C. ubiquitum, aunque C. andersoni y $C$. fayeri también se reportan ${ }^{(2,7,8)} ;$. parvum es una especie zoonótica ${ }^{(9,10)}$. A la fecha, no se han reportado tratamientos efectivos contra este parásito ${ }^{(3,11)}$. El diagnóstico de la infección por Cryptosporidium mediante métodos moleculares como la reacción en cadena de la polimerasa (PCR) ha permitido identificar especies y genotipos del parásito, así como caracterizar la dinámica de transmisión de la infección en los seres humanos y en los animales ${ }^{(10,12)}$. Así, se conoce la distribución geográfica de las especies y la diversidad genética del parásito. En el ganado ovino se han reportado diferentes especies de Cryptosporidium en EUA, Reino Unido, Italia, Bélgica, España, Túnez, China, Australia y Brasil, principalmente ${ }^{(12,13)}$. Los análisis moleculares han confirmado que $C$. parvum infecta de forma natural a corderos y cabritos ${ }^{(14)}$. En México, este parásito se identificó por primera vez en bovinos lactantes en el año de 1983, mediante microscopía ${ }^{(15)}$; sin embargo, en el país hay pocos estudios sobre la infección por Cryptosporidium spp., en ovinos ${ }^{(5,15)}$.

El objetivo de la investigación fue determinar la frecuencia de la infección por Cryptosporidium spp., en corderos lactantes de razas de pelo, mantenidos en pastoreo en la región de la Huasteca Alta del estado de Veracruz, México, y realizar la identificación de la especie de los ooquistes encontrados, utilizando herramientas moleculares.

\section{Material y métodos}

\section{- Sitio de estudio}

El estudio se desarrolló en la región de la Huasteca Alta del estado de Veracruz, México, la cual se localiza en la zona norte del estado, en las coordenadas $21^{\circ} 46^{\prime} \mathrm{N}$ y $98^{\circ} 27^{\prime} \mathrm{O}$, a una altura de 1 a 150 msnm. Está integrada por siete municipios: Pánuco, Tampico Alto, 
Tempoal, Ozuluama, Tantoyuca, Naranjos y Tamiahua (Figura 1). La temperatura media anual es $24.4{ }^{\circ} \mathrm{C}$ y la precipitación promedio anual es de $1,239 \mathrm{~mm}$. La región cuenta con diversidad climática amplia, que va del clima cálido-extremoso al templado subhúmedo ${ }^{(16)}$.

Figura 1: Región de la Huasteca Alta del estado de Veracruz, México, municipios incluidos en la investigación

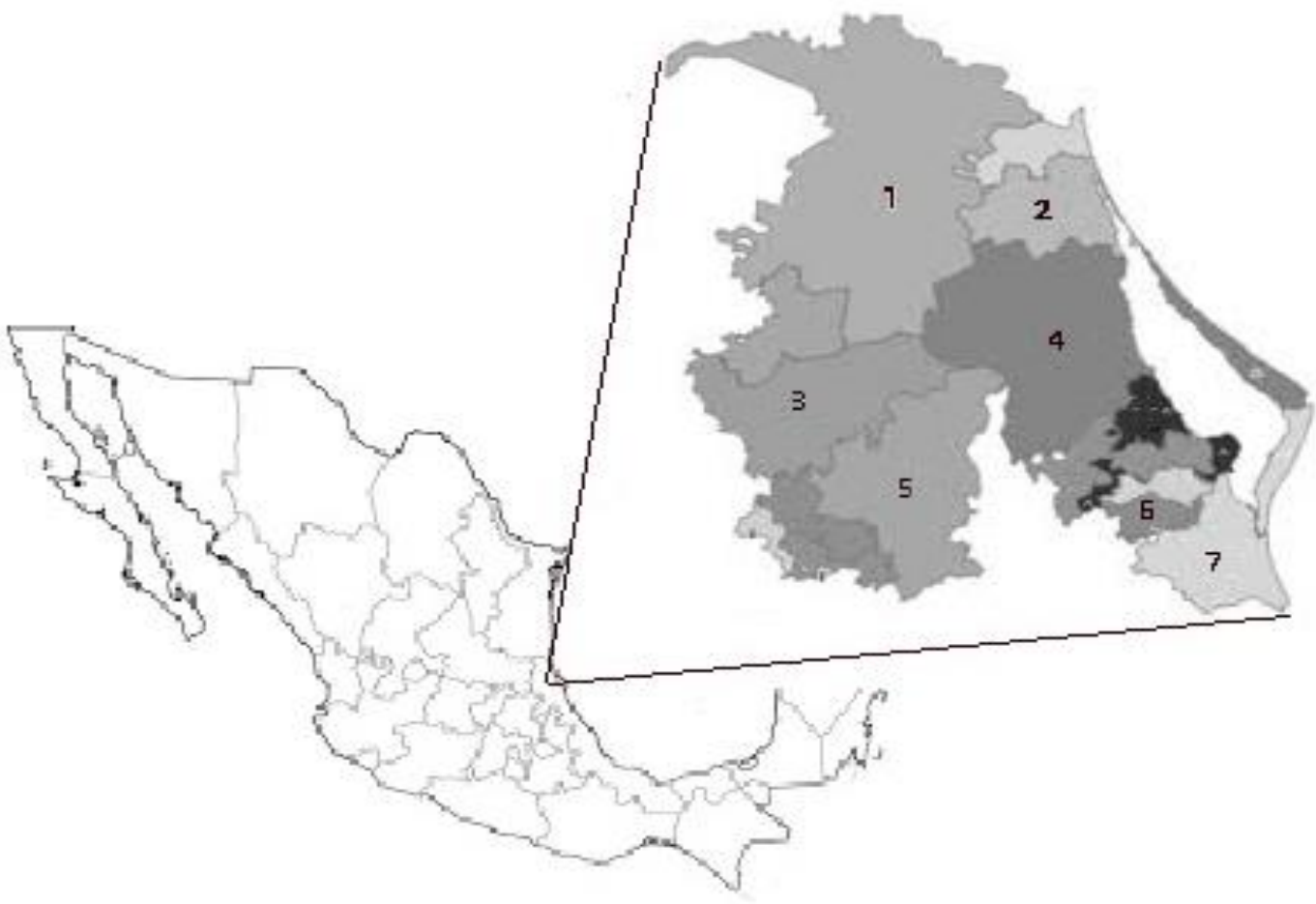

1. Panuco

2. Tampico alto

3. Tempoal

4. Ozuluama

5. Tantoyuca

6. Naranjos

7. Tamiahua

\section{- Granjas y manejo de animales •}

La región de la Huasteca Alta cuenta con 6,678 ovejas en etapa reproductiva y 1,991 $\operatorname{corderos}^{(17)}$. El método epidemiológico de conveniencia de Thrusfield ${ }^{(18)}$, se usó para seleccionar el $10 \%$ de la población de corderos; 21 granjas de ganado ovino distribuidos en 
siete municipios de la región bajo estudio, Panuco, Tampico Alto, Tempoal, Ozuluama, Tantoyuca, Naranjos y Tamiahua, tres granjas por cada uno de ellos; la inclusión de las granjas fue en función de que contaran con ovinos encastados de razas de pelo, principalmente Pelibuey, Black Belly y Katahdin, y que los productores mostraran interés por participar en el estudio. Los ovinos se mantuvieron bajo un sistema de libre pastoreo en praderas naturales o cultivadas, o ambas, con pastos estrella (Cynodon plectostachyus), pangola (Digitaria decumbens), guinea (Panicum maximun) y brizantha (Brachiaria brizantha), sin ningún control reproductivo, y sin aplicar prácticas de manejo y control sanitario.

\section{- Toma de muestras •}

Las granjas se visitaron en una sola ocasión, eligiendo al azar diez animales clínicamente sanos de la población de corderos que tuviera entre 7 y 21 días de edad, ya que en este intervalo de edad son más susceptibles a la infección ${ }^{(11)}$. Se tomaron muestras de excremento directamente del recto, anotando el nombre de la granja, identificación del animal y su edad; las muestras se conservaron a $4{ }^{\circ} \mathrm{C}$, y se procesaron en el laboratorio dentro de 24 a $72 \mathrm{~h}$ después de colectada la muestra.

\section{- Limpieza y concentración de las muestras fecales •}

Previo al diagnóstico microscópico y molecular, se realizó la limpieza de las muestras fecales $^{(2)}$, tomando $15 \mathrm{~g}$ de heces de cada muestra que se transfirieron a tubos de $50 \mathrm{ml}$ que contenían $35 \mathrm{ml}$ de agua destilada $\left(\mathrm{dH}_{2} \mathrm{O}\right)$. El contenido de cada tubo se mezcló vigorosamente durante $2 \mathrm{~min}$, pasando la muestra a través de una malla de poro de $50 \mathrm{~mm}$ a un segundo tubo de $50 \mathrm{ml}$, y el volumen final se ajustó a $50 \mathrm{ml}$ con $\mathrm{dH}_{2} \mathrm{O}$. Los tubos se centrifugaron a 1,800 xg durante $15 \mathrm{~min}$, y el sobrenadante se desechó; el sedimento se suspendió de nuevo en $25 \mathrm{ml}$ de $\mathrm{dH}_{2} \mathrm{O}$ y se mezcló vigorosamente durante $2 \mathrm{~min}$. Se añadieron $25 \mathrm{ml}$ de cloruro de cesio $(\mathrm{CsCl})$ a una concentración de $1.4 \mathrm{~g} \mathrm{~L}^{-1}$ en cada tubo y 
se centrifugó a $300 \mathrm{xg}$ durante $20 \mathrm{~min}$. Solamente $4 \mathrm{ml}$ de sobrenadante se aspiraron de la parte superior de cada muestra, los cuales se transfirieron a un tubo de centrífuga, y se agregó $\mathrm{dH}_{2} \mathrm{O}$ hasta obtener un volumen final de $15 \mathrm{ml}$. Las muestras se centrifugaron a 1,800 xg durante 15 min y se lavó el material dos veces con $\mathrm{dH}_{2} \mathrm{O}$, posteriormente el pellet final fue resuspendido en $500 \mu \mathrm{l}$ de $\mathrm{dH}_{2} \mathrm{O}$.

\section{- Diagnóstico microscópico}

Un frotis fecal se realizó con $100 \mu \mathrm{l}$ del material concentrado previamente con $\mathrm{CsCl}$, diluyendo la muestra 1:1 con agua oxigenada. Después se dejó secar por $24 \mathrm{~h}$ a temperatura ambiente $\left(25^{\circ} \mathrm{C}\right)$, se procesaron mediante la técnica de tinción ácido-alcohol resistente de Kinyoun $^{(19)}$, y se observó el frotis en un microscopio (LCD Digital, Leica®) a 100X. La muestra se consideró negativa al no observar ningún ooquiste después de revisar seis campos microscópicos en cada portaobjetos (laminilla de vidrio $75 \mathrm{~mm}$ x $26 \mathrm{~mm}$ ); con la finalidad de minimizar las lecturas de falsos positivos la muestra se consideró positiva cuando se observaron al menos $\geq 5$ ooquistes de Cryptosporidium spp., los cuales se presentan de forma esférica y teñidos de color rosa brillante ${ }^{(20)}$.

\section{- Extracción de ADN}

La extracción de ADN total de cada muestra se realizó a partir del material concentrado previamente con $\mathrm{CsCl}$, utilizando el paquete comercial DNeasy Tissue Kit (Qiagen ${ }^{\circledR}$, Valencia, CA), de acuerdo a lo recomendado por el proveedor ${ }^{(11)}$. 


\section{- Amplificación del Gen 18S rARN. •}

Un fragmento de la región 18S rARN del gen de Cryptosporidium spp., se amplificó utilizando una PCR anidada con los iniciadores descritos Xiao et $a l^{(21)}$, (5'-TTCTAGAGC TAATACATGCG-3' y 5'- CCCTAATCCTTCGAAACAGGA-3' para la PCR primaria, y 5'GGAAGGGTTGTATTTATTAGATAAAG-3' y 5'-AAGGAGTAAGGAACAACCTCCA3' para la PCR secundaria. Para la primera PCR, la reacción contenía: buffer 1X de PCR (Sigma-Aldrich ${ }^{\circledR}$ ); $\quad \mathrm{MgCl}_{2}, \quad 3 \mathrm{mM}$ (Sigma-Aldrich ${ }^{\circledR}$ ); $\quad$ dNTP (Invitrogen ${ }^{\circledR} \quad$ Life Technologies), $0.2 \mathrm{mM}$ de cada uno; Taq polimerasa (Invitrogen ${ }^{\circledR}$ Life Technologies) 2.5 $\mathrm{U}$; Albumina sérica bovina (BSA; Sigma-Aldrich $\left.{ }^{\circledR}\right) 2.5 \mathrm{ml}(0.1 \mathrm{~g} / 10 \mathrm{ml})$ y $1 \mu \mathrm{M}$ de cada iniciador (New England Biolabs, Beverly, MA), en un volumen de $50 \mu 1$ de reacción. La mezcla se sometió a 35 ciclos, cada uno de $94{ }^{\circ} \mathrm{C}$ durante $45 \mathrm{seg}, 59{ }^{\circ} \mathrm{C}$ durante $45 \mathrm{seg}$, y 72 ${ }^{\circ} \mathrm{C}$ durante $1 \mathrm{~min}$, un arranque en caliente a $94{ }^{\circ} \mathrm{C}$ durante $3 \mathrm{~min}$. También se incluyó un paso de extensión final a $72{ }^{\circ} \mathrm{C}$ por $7 \mathrm{~min}$. Para la segunda PCR la reacción fue idéntica a la primera, excepto que se utilizó una concentración de $1.5 \mathrm{mM} \mathrm{de} \mathrm{MgCl}_{2}$. Las condiciones de amplificación fueron las siguientes: 40 ciclos de $94{ }^{\circ} \mathrm{C}$ durante $30 \mathrm{seg}, 58^{\circ} \mathrm{C}$ durante $90 \mathrm{seg}$, y $72{ }^{\circ} \mathrm{C}$ durante $2 \mathrm{~min}$, con un arranque en caliente a $94{ }^{\circ} \mathrm{C}$ durante 3 min y una etapa de extensión final de $72{ }^{\circ} \mathrm{C}$ durante $7 \mathrm{~min}$, utilizando un Termociclador Bio-Rad® T100.

Los productos de la PCR se sometieron a electroforesis en un gel de agarosa al $1 \%$ en TAE (40 mM Tris-acetato, $1 \mathrm{mM}$ EDTA). El marcador de peso molecular utilizado fue de $1 \mathrm{~kb}$ (Invitrogen ${ }^{\circledR}$ ) para identificar la banda correspondiente a $830 \mathrm{pb}$. Controles positivos y negativos se incluyeron en todos los casos. Después se tiñó el gel con bromuro de etidio a una concentración de $5 \mathrm{mg} \mathrm{ml}^{-1}$ durante $15 \mathrm{~min}$. Los resultados de esta fase se observaron en un Transiluminador Bio Doc.it Imagin System®.

\section{- Identificación molecular 。}

Las muestras identificadas como positivas a Cryptosporidium spp., se purificaron con el paquete comercial Min Elute PCR Purification Kit, (Qiagen ${ }^{\circledR}$, Valencia, CA). Las muestras purificadas se secuenciaron en ambos sentidos, utilizando los iniciadores ya descritos, con el sistema de secuenciación BigDye Terminator Cycle Sequencing utilizado en el equipo 3100 Genetic Analyzer (Applied Biosystems), en el Laboratorio Nacional de Genómica (CINVESTAV Unidad Irapuato, Guanajuato, México). Las secuencias obtenidas en el 
estudio fueron alineadas y comparadas por homología con las reportadas en el GenBank, empleando el programa BLAST (Basic Local Alignment Search Tools) ${ }^{(22)}$.

\section{- Análisis de la información 。}

La frecuencia de corderos positivos a la presencia de ooquistes de Cryptosporidium spp., se calculó en el total de las muestras, por municipio y por granja incluida en el estudio, así como por intervalo de edad de los corderos, considerando los resultados obtenidos por microscopia y por técnicas moleculares.

\section{\| Resultados}

La técnica parasitoscópica de frotis fecal teñido por el método de Kinyoun, permitió identificar 41 muestras positivas a Cryptosporidium spp. La frecuencia general de casos fue de $19.5 \%$ (41/210; IC 95\% 14-25). La frecuencia entre rebaños varió de 10 a $50 \%$ (Cuadro 1), existiendo $62 \%$ (13/21) de las granjas con al menos un cordero infectado. En el grupo de corderos de 7 a 14 días de edad se identificó una frecuencia de 10.4 \% (22/210; IC95\% 6-15) mientras que en el grupo de 15 a 21 días fue $9 \%$ (19/210; IC95\% 5-13). En los siete municipios estudiados se encontraron corderos positivos a la presencia de ooquistes del parásito; la frecuencia en los municipios se presentó en un rango de $6.7 \%$ (2/30; IC95\% 1 23) en Pueblo Viejo a 36.7 \% (11/30; IC95\% 20-56) en Tamiahua (Cuadro 2). 
Cuadro 1: Frecuencia de Cryptosporidium spp., en la región de la Huasteca Alta de Veracruz, México, distribuida por granja y grupo de edad

\begin{tabular}{|c|c|c|c|c|c|c|c|c|}
\hline \multirow[t]{2}{*}{ Municipio } & \multirow[t]{2}{*}{ Granja } & \multirow[t]{2}{*}{+} & \multirow[t]{2}{*}{-} & \multirow{2}{*}{$\begin{array}{c}\text { Edad 7-14 } \\
\text { días + }\end{array}$} & \multirow{2}{*}{$\begin{array}{l}\text { Edad 15- } 21 \\
\quad \text { días - }\end{array}$} & \multicolumn{2}{|c|}{$\begin{array}{c}\text { Frecuencia por } \\
\text { grupo de edad (\%) }\end{array}$} & \multirow[t]{2}{*}{$\begin{array}{c}\text { Frecuencia } \\
\text { por granja (\%) }\end{array}$} \\
\hline & & & & & & $7-14$ & $15-21$ & \\
\hline Naranjos & $\begin{array}{l}1 \\
2 \\
3\end{array}$ & $\begin{array}{l}0 \\
4 \\
3\end{array}$ & $\begin{array}{l}10 \\
6 \\
7\end{array}$ & $\begin{array}{l}0 \\
3 \\
1\end{array}$ & $\begin{array}{l}0 \\
1 \\
2\end{array}$ & 13.3 & 10.0 & $\begin{array}{c}0 \\
40 \\
30\end{array}$ \\
\hline Ozuluama & $\begin{array}{l}1 \\
2 \\
3\end{array}$ & $\begin{array}{l}4 \\
0 \\
4\end{array}$ & $\begin{array}{c}6 \\
10 \\
6\end{array}$ & $\begin{array}{l}2 \\
0 \\
1\end{array}$ & $\begin{array}{l}2 \\
0 \\
3\end{array}$ & 10 & 16.6 & $\begin{array}{c}40 \\
0 \\
40\end{array}$ \\
\hline Pánuco & $\begin{array}{l}1 \\
2 \\
3\end{array}$ & $\begin{array}{l}3 \\
0 \\
1\end{array}$ & $\begin{array}{c}7 \\
10 \\
9\end{array}$ & $\begin{array}{l}2 \\
0 \\
0\end{array}$ & $\begin{array}{l}1 \\
0 \\
1\end{array}$ & 6.6 & 6.6 & $\begin{array}{c}30 \\
0 \\
10\end{array}$ \\
\hline Pueblo viejo & $\begin{array}{l}1 \\
2 \\
3\end{array}$ & $\begin{array}{l}0 \\
2 \\
0\end{array}$ & $\begin{array}{c}10 \\
8 \\
10\end{array}$ & $\begin{array}{l}0 \\
0 \\
0\end{array}$ & $\begin{array}{l}0 \\
2 \\
0\end{array}$ & 0 & 6.6 & $\begin{array}{c}0 \\
20 \\
0\end{array}$ \\
\hline Tamiahua & $\begin{array}{l}1 \\
2 \\
3\end{array}$ & $\begin{array}{l}3 \\
3 \\
5\end{array}$ & $\begin{array}{l}7 \\
7 \\
5\end{array}$ & $\begin{array}{l}2 \\
2 \\
2\end{array}$ & $\begin{array}{l}1 \\
1 \\
3\end{array}$ & 20 & 16.6 & $\begin{array}{l}30 \\
30 \\
50\end{array}$ \\
\hline Tantoyuca & $\begin{array}{l}1 \\
2 \\
3\end{array}$ & $\begin{array}{l}2 \\
4 \\
0\end{array}$ & $\begin{array}{c}8 \\
6 \\
10\end{array}$ & $\begin{array}{l}2 \\
3 \\
0\end{array}$ & $\begin{array}{l}0 \\
1 \\
0\end{array}$ & 16.7 & 3.3 & $\begin{array}{c}20 \\
40 \\
0\end{array}$ \\
\hline Tempoal & $\begin{array}{l}1 \\
2 \\
3\end{array}$ & $\begin{array}{l}0 \\
3 \\
0\end{array}$ & $\begin{array}{c}10 \\
7 \\
10\end{array}$ & $\begin{array}{l}0 \\
2 \\
0\end{array}$ & $\begin{array}{l}0 \\
1 \\
0\end{array}$ & 6.6 & 3.3 & $\begin{array}{c}0 \\
30 \\
0\end{array}$ \\
\hline$\overline{\text { Total }}$ & 21 & 41 & 169 & 22 & 19 & 10.4 & 9.0 & \\
\hline
\end{tabular}

Cuadro 2: Frecuencia de Cryptosporidium spp., detectada por microscopía y de identificación de $C$. parvum mediante PCR, en corderos

\begin{tabular}{lcccccc}
\hline Municipio & $\mathrm{n}$ & $\begin{array}{c}\text { Cryptosporidium spp. } \\
\text { (microscopía) }\end{array}$ & $\begin{array}{c}\text { Frecuencia } \\
(\%)\end{array}$ & $\mathrm{n}$ & $\begin{array}{c}\text { C. parvum } \\
(\text { PCR })\end{array}$ & $\begin{array}{c}\text { Frecuencia } \\
(\%)\end{array}$ \\
\hline Naranjos & 30 & 7 & 23.4 & 7 & 1 & 14.2 \\
Ozuluama & 30 & 8 & 26.6 & 8 & 2 & 25.0 \\
Pánuco & 30 & 4 & 13.3 & 4 & 1 & 25.0 \\
Pueblo viejo & 30 & 2 & 6.7 & 2 & 0 & 0 \\
Tamiahua & 30 & 11 & 36.7 & 11 & 4 & 36.3 \\
Tantoyuca & 30 & 6 & 20.0 & 6 & 3 & 50.0 \\
Tempoal & 30 & 3 & 10.0 & 3 & 0 & 0 \\
\hline Total & 210 & 41 & 19.5 & 41 & 11 & 26.8 \\
\hline
\end{tabular}


Del total de muestras recolectadas, 11 resultaron positivas por microscopía y por la prueba de PCR anidada, mientras que 30 muestras positivas por microscopía no amplificaron el segmento en la prueba de PCR anidada; el resto de las muestras fueron negativas en ambas pruebas, arrojando una frecuencia de $26.8 \%$ (11/41; IC95\% 4-43) de muestras que amplificaron el segmento, observándose que por municipios se tuvo un rango de $14.3 \%$ (1/7; IC95\% .07-58) a $50 \%$ (3/6; IC95\% 13-86) (Cuadro 2).

La identificación de la especie de Cryptosporidium presente en las muestras de ADN de los corderos positivos por microscopía, mostró que tuvieron una homología del $100 \%$ para $C$. parvum (Accesión GenBank AF093493). Seis muestras positivas a C. parvum correspondieron al grupo de corderos de 7 a 14 días de edad y cinco al grupo de 15 a 21 días de edad. No fue posible identificar alguna otra especie o genotipo en las muestras.

\section{Discusión}

La infección por Cryptosporidium spp., se caracteriza por afectar primordialmente a los animales neonatos y se ha estudiado en bovinos, pero en ovinos está poco documentada, en particular en sistemas de pastoreo ${ }^{(23)}$. Algunos estudios han mostrado la frecuencia de Cryptosporidium utilizando diversas técnicas de diagnóstico. En México la información sobre la frecuencia de la infección en ovinos es escasa; un estudio desarrollado en el Estado de México realizado en 37 granjas con corderos estabulados se identificó una prevalencia de $34.3 \%{ }^{(15)}$, y en el municipio de Perote, Veracruz, México, en ovinos de razas de pelo mantenidos en sistemas de pastoreo se identificó, una prevalencia de $67.5 \%$, mientras que en los corderos menores de un mes fue de $88.2 \%$, todos las granjas fueron positivas al parásito, identificado mediante la técnica de microscopia mediante la cual sólo es posible identificar el género Cryptosporidium ${ }^{(5)}$; siendo el diagnóstico molecular la manera más certera de identificar especie ${ }^{(9,11)}$.

En el presente estudio, la frecuencia general de casos fue de $19.5 \%$ y por grupo de edad, $10.5 \%$ en los de 7-14 días de edad y $9 \%$ en los de 15-21 días, valores menores que los reportados en los estudios desarrollados en México; solo el $62 \%$ de los rebaños presentaron ovinos positivos, aunque en todos los municipios hubo al menos una granja con casos positivos a Cryptosporidium spp. Las diferencias entre estos estudios son comprensibles porque cada uno de ellos se desarrolló bajo condiciones particulares de tiempo, diseño del 
muestreo, diversidad en las prácticas de manejo, y en última instancia a la competencia de la persona que realiza el diagnóstico microscópico, así como al criterio para considerar una muestra positiva.

En la literatura hay estudios desarrollados con la misma finalidad que el presente. Así, en Bélgica se reporta una prevalencia en corderos menores de un mes de vida de $13.1 \%$ (18/137), identificando positivos solo en el $40 \%$ de los diez rebaños estudiados ${ }^{(22)}$; mientras que en Zambia, la prevalencia fue de $12.5 \%$ en corderos menores de un mes ${ }^{(14)}$. En Turquía $^{(24)}$, indican en corderos de esta misma edad una prevalencia de $38.8 \%$ (155/400), distribuida en el $90 \%$ (18/20) de las granjas observadas, mostrando que de acuerdo con los grupos de edad, la frecuencia en corderos de una semana de edad fue $44.4 \%(67 / 151)$, en corderos de dos semanas fue $37.5 \%$ (39/104), en los de tres semanas $40 \%$ (38/95) y $22 \%$ (11/50) en los de cuatro semanas de edad. En la India, se identificó una infección de $65 \%$ en corderos de menos de un mes de edad ${ }^{(25)}$; en Zaragoza, España, Cryptosporidium spp., se presentó en corderos de 14 días de edad ${ }^{(26)}$. La comparación entre estudios desarrollados en otros países con el nuestro es difícil; la información generada en ellos permite confirmar que este parásito infecta con mayor frecuencia a corderos menores de 30 días de edad, como se reporta en la literatura ${ }^{(11)}$, y la prevalencia es tan diversa como los sistemas de producción.

La frecuencia de la infección por Cryptosporidium spp., puede ser influenciada por diferentes factores en mayor o menor intensidad, tales como el sistema de crianza, estado nutricional, el estado inmunológico de los animales, la estación del año y el manejo sanitario en las granjas. Sin embargo, la edad es un factor considerado como marcador de riesgo a contraer la infección; los animales jóvenes, en especial los lactantes, son los más propensos a sufrir esta enfermedad, y a ello se le adicionan al menos otros dos factores de riesgo, el estado inmunológico de los animales y el manejo sanitario ${ }^{(25-28)}$. La exposición inicial de los neonatos a la infección ocurre en las áreas de parición, como consecuencia de la eliminación de ooquistes por parte de las borregas gestantes; por lo general los ooquistes contaminan la ubre, el agua, el alimento y las áreas donde habitan los corderos; así, el sistema de manejo interviene en la probabilidad de transmisión del protozoario entre animales infectados y susceptibles ${ }^{(27)}$. La infección en el hospedador inmunocompetente es autolimitada y deja en el sujeto una inmunidad sólida ante la re-infección; lo contrario, ocurre en sujetos con deficiencias linfocitarias o de gammaglobulinas; hay que recordar que los ooquistes son infectantes al momento de excretarse de su hospedero ${ }^{(2)}$. La resistencia de los ooquistes en el medio ambiente también es importante, ya que sobreviven en camas, paredes, comederos, bebederos y utensilios, y mantienen su capacidad infectante durante largos periodos de tiempo; además, el contacto entre los animales recién nacidos y los adultos representa una importante fuente de contaminación y de dispersión del parásito en su fase infectante ${ }^{(12,29)}$. La diseminación del parásito ocurre cuando el excremento contaminado se deposita en el suelo, de tal forma es factible que los ooquistes se transporten por agua o aire a los sitios o materiales que actúan como vehículos de contagio ${ }^{(17,10)}$. En sistemas de producción 
intensivos se detecta una prevalencia más alta que en los manejados en pastoreo ${ }^{(4,15)}$, probablemente debido a que las condiciones de confinamiento favorecen la presencia de la infección como se ha demostrado en becerros lactantes ${ }^{(2,26,30)}$.

En la presente investigación, $C$. parvum fue la única especie identificada en las muestras procesadas; esta especie es la que se presenta con mayor frecuencia en los rumiantes domésticos, particularmente en animales jóvenes ${ }^{(31-34)}$, además de ser una especie con capacidad zoonótica ${ }^{(9,17)}$. En México, $C$. parvum ha sido identificada mediante biología molecular en ganado bovino lechero ${ }^{(33)}$; el hallazgo de su presencia en el ganado ovino incluido en el presente estudio, representa el primer reporte en el país para esta especie animal.

\section{Conclusiones e implicaciones}

Los resultados observados en este estudio muestran que la frecuencia de la infección por Cryptosporidium spp., en corderos es moderada en la población estudiada; sin embargo, denota la amplia distribución del parásito en la región. La identificación de C. parvum como única especie presente en las muestras estudiadas, confirma que la misma es de carácter cosmopolita y la más frecuente en rumiantes; así, este hallazgo es de importancia epidemiológica, porque sugiere que los animales infectados pueden actuar como diseminadores del parásito para otros animales domésticos y silvestres, e incluso para los seres humanos, particularmente para los manejadores de ganado.

\section{Agradecimientos}

Se agradece a los ovinocultores que participaron en este estudio por su amplia colaboración. Este proyecto (4559.12-P) fue financiado por el Tecnológico Nacional de México. 


\section{- Literatura citada:}

1. Karanis P, Kourenti C, Smith H. Waterborne transmission of protozoan parasites: a worldwide review of outbreaks and lessons learnt. J Water Health 2007;5:1-38.

2. Fayer R, Santín M, Macarisin D. Cryptosporidium ubiquitum n. sp., in animals and humans. Vet Parasitol 2010;172:23-32.

3. Razzolinia M, Souza De L.M, Hachichc EM, Zanoli MI, Nardoccia AC. Giardia and Cryptosporidium infection risk by simultaneous exposure to drinking water. Microbl Risk Anal 2016;4:1-6.

4. Quílez J, Torres E, Chalmers RM, Hadfield SJ, Del Cacho E, Sánchez-Acedo C. Cryptosporidium genotypes and subtypes in lambs and goat kids in Spain. Appl Environ Microbiol 2008;74:6026-6031.

5. Romero-Salas D, Alvarado EC, Cruz RA, Aguilar DM, Ibarra PN, Merino CJ, Pérez LA, Hernández TJ. Prevalence of Cryptosporidium in small ruminants from Veracruz, Mexico. BMC Vet Res 2016;12:14.

6. Castro-Hermida JAM, González W, Mezo M. Natural infection by Cryptosporidium parvum and Giardia duodenalis in sheep and goats in Galicia (New Spain). Small Ruminant Res 2007;72:96-100.

7. Santın M, Trout JM, Xiao L, Zhou L, Greiner E, Fayer R. Prevalence and age-related variation of Cryptosporidium species and genotypes in dairy calves. Vet Parasitol 2004;122:103-117.

8. Fayer R, Santín M. Cryptosporidium xiaoi n. sp. (Apicomplexa: Cryptosporidiidae) in sheep (Ovis aries). Vet Parasitol 2009;164:192-200.

9. Xiao L, Ryan UM. Cryptosporidiosis: an update in molecular epidemiology. Curr Opin Infec Dis 2004;17:483-490.

10. Khalil S, Mirdhaa BR, Paulb J, Pandaa A, Makhariac G, Chaudhrya R, Bhatnagard S. Development and evaluation of molecular methods for detection of Cryptosporidium spp. in human clinical samples. Exp Parasitol 2016;170:207-213.

11. Santin M, Trout JM, Fayer R. Prevalence and molecular characterization of Cryptosporidium and Giardia species and genotypes in sheep in Maryland. Vet Parasitol 2007;146:17-24. 
12. Zucatto AS, Aquino MCC, Inácio SV, Figueiredo RN, Pierucci JC, Perri SHV, Meireles MV, Bresciani KDS. Molecular characterization of Cryptosporidium spp. in lambs in the South Central region of the State of São Paulo. Arq Bras Med Vet Zoot Belo Horizonte 2015;67:1678-7067.

13. Wang Y, Feng Y, Cui B, Jian F, Ning C, Wang R, Zhang L, Xiao L. Cervine genotype is the major Cryptosporidium genotype in sheep in China. Parasitol Res 2010;106:341347.

14. Goma FY, Geurden V, Siwila J, Phiri IG, Gabriel S, Claerebout E, Verccruyse J. The prevalence and molecular characterization of Cryptosporidium spp. in small ruminants in Zambia. Small Ruminant Res 2007;72:77-80.

15. Alonso-Fresán MU, García-Alvarez A, Salazar-García F, Vazquez-Chagoyan JC, Pescador-Salas N, Saltijeral-Oaxaca J. Prevalence of Cryptosporidium spp. in asymptomatic sheep in family flocks from México State. J Vet Med Series B 2005;52:482-483.

16. García E. Modificación al sistema de clasificación climática de Koeppen. $2^{\mathrm{a}}$ ed. Instituto de Geografía. Universidad Nacional Autónoma de México. 1973.

17. SAGARPA. Anuario Estadístico y Geográfico del estado de Veracruz http://www.sagarpa.gob.mx, Consultado 12 May, 2012.

18. Thusfield M. Veterinary epidemiology. $2^{\text {nd }}$ ed. London: Blackwell Science; 1995.

19. Fayer R, Trout JM, Craczyk TD, Lewis EJ. Prevalence of Cryptosporidium, Giardia, and Eimeria infections in post-weaned and adult cattle on three Maryland farms. Vet Parasitol 2000;93:103-112.

20. Baxby D, Blundell N, Hart CA. The development and performance of a simple, sensitive method for the detection of Cryptosporidium oocysts in faeces. J Hyg (Lond) 1984;93:317-23.

21. Xiao L, Morgan U, Limor J, Escalante A, Arrowood M, Shulaw W, Thompson RCA, Fayer R, Lal A. Genetic diversity within Cryptosporidium parvum and related Cryptosporidium species. App Environ Microbiol 1999;65:3386-3391.

22. Stephen AF, Madden TL, Schaffer AA, Zhang J, Zhang Z, Miller W, Lipman DJ. Gapped BLAST and PSI-BLAST: a new generation of protein database search programs. Nucleic Acids Res 1997;25:3389-3402.

23. Al-Habsi K, Yang R, Williams A, Miller D, Ryan U, Jacobson C. Zoonotic Cryptosporidium and Giardia shedding by captured rangeland goats. Vet Parasitol: Region Stud Rep 2017;7:32-35 
24. Geurden T, Thomas P, Casaert S, Vercruysse J, Claerebout E. Prevalence and molecular characterization of Cryptosporidium and Giardia in lambs and goat kids in Belgium. Vet Parasitol 2008;155:142-145.

25. Sari B, Arslan MO, Gicik Y, Kara M, Tasci GT. The prevalence of Cryptosporidium species in diarrheic lambs in Kars province and potential risk factors. Trop Anim Health Prod 2009;41:819-826.

26. Ahamed, I, Yadav, A, Katoch, R, Godara, R, Saleem, Taniya, Nisar, NA. Prevalence and analysis of associated risk factors for Cryptosporidium infection in lambs in Jammu district. J Parasit Dis 2015;39:414-417.

27. Causapé AC, Quilez J, Sanchez-Acedo C, del Cacho E, López-Bernad F. Prevalence and analysis of potential risk factors for Cryptosporidium parvum infection in lambs in Zaragoza (northeastern Spain). Vet Parasitol 2002;104:287-298.

28. Xiao L, Fayer R. Molecular characterization of species and genotypes of Cryptosporidium and Giardia and assessment of zoonotic transmission. Int J Parasitol 2008;38:1239-1255.

29. Kim CW. Laboratory animal models for experimental cryptosporidiosis: a mini-review. Res Rev Parasitol 1994;54:13-28.

30. Vergara C, Quiles J. Criptosporidiosis: una zoonosis parasitaria. Rev MVZ Córdoba 2004;9:363-372.

31. Taylan-Ozkana A, Yasa-Durub S, Uslucac S, Lysend C, Yed J, Roelligd DM, Fenge Y, Xiao L. Cryptosporidium species and Cryptosporidium parvum subtypes in dairy calves and goat kids reared under traditional farming systems in Turkey. Exp Parasitol 2016;170:16-20.

32. Mueller-Doblies D, Giles M, Elwin K, Smith RP, Clifton-Hadley FA, Chalmers RM. Distribution of Cryptosporidium species in sheep in the UK. Vet Parasitol 2008;154:214-219.

33. Castillo-García C, Cruz-Vázquez C, López RR, Sánchez GM, Rosario CR, Vitela MI, Medina EL. Frequency and molecular identification of Cryptosporidium spp in confined suckling dairy calves in Aguascalientes, Mexico. Téc Pecu Méx 2009;47:425-434.

34. Paoletti B, Giangaspero A, Gatti A, Iorio R, Cembalo D, Milillo P, Traversa D. Immunoenzymatic analysis and genetic detection of Cryptosporidium parvum in lambs from Italy. Exp Parasitol 2009;122:349-352. 